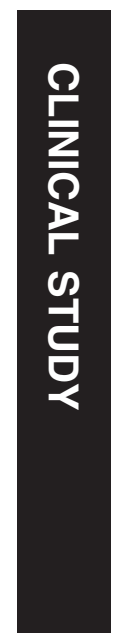

\title{
Parental smoking and childhood refractive error: the STARS study
}

${ }^{1}$ Singapore National Eye Center, 11 Third Hospital Avenue, Singapore, Singapore

${ }^{2}$ Singapore Eye Research Institute, 11 Third Hospital Avenue, Singapore, Singapore

${ }^{3}$ Epidemiology and Public Heath and Ophthalmology, Yong Loo Lin School of Medicine, National University of Singapore, Singapore, Singapore

${ }^{4}$ Health Services Research Unit, Centre for Eye Research Australia, Department of Ophthalmology, University of Melbourne, Melbourne, Victoria, Australia

Correspondence: JV Iyer, Singapore National Eye Centre, 11 Third Hospital Avenue, Singapore 168751, Singapore Tel: +65 62277255; Fax: +65 62277290 E-mail: jayant.venkatramani @snec.com.sg.

Received: 28 November 2011

Accepted in revised form:

2 July 2012

Published online: 31 August 2012

\begin{abstract}
Purpose To assess the relationship between parental smoking and childhood refractive errors in Singapore Chinese children aged 6-72 months recruited through the STrabismus, Amblyopia, and Refractive errors in Singaporean children study. Methods A total of 4164 children were recruited, with a positive response rate of $72.3 \%(n=3009)$. Cycloplegic refraction measurements were obtained from all children by trained eye professionals. Parents underwent an interviewer-administered questionnaire with information on demographics, lifestyle, and parental smoking history being obtained. Results Spherical equivalent readings were obtained for $87.7 \%$ of the children. In all, $52.1 \%$ were male $(n=1375)$. The overall prevalence of myopia (at least $-0.5 \mathrm{D}$ ) was $11.0 \%$. Overall, $37.1 \%$ of the fathers interviewed gave a history of smoking. Among the mothers interviewed, $9.2 \%$ gave a history of smoking, $6.6 \%$ had smoked during the child's life, and $2.2 \%$ had smoked during the pregnancy. Maternal history of ever smoking, smoking during child's life, and smoking during pregnancy were associated with decreased odds ratio (OR) of childhood myopia (OR $0.50(P=0.01)$, OR $0.39(P=0.01)$, and OR $0.3(P=0.14)$, respectively). Paternal history of smoking was associated with decreased OR of childhood myopia (OR of $0.72(P=0.02))$.

Conclusion In light of this finding of an inverse association between parental smoking and childhood myopia, further studies are suggested to better understand the role of nicotinic acetylcholine receptor pharmacology in ocular development. This may pave the way for the development of targeted treatment strategies for prevention of myopia.
\end{abstract}

Eye (2012) 26, 1324-1328; doi:10.1038/eye.2012.160; published online 31 August 2012

Keywords: myopia; smoking; parental

\section{Introduction}

Refractive error is one of the leading causes of visual impairment worldwide. ${ }^{1}$ It is projected that one-third of the world's population will have myopia by the year $2020 .^{2}$ This poses serious public health and economic concerns.

Aetiology and causative factors in the development of childhood myopia have yet to be comprehensively ascertained.

Prevalence of myopia varies across different races, suggesting some genetic basis underpinning myopia. Prevalence of myopia in young Chinese children has been noted to be generally higher-ranging from 5.5 to $38.1 \%$ in children aged 6 months to 15 years of age $^{3-5}$ - compared with that found by studies in the West where prevalence rates ranged from 0.8 to $11.9 \%$ in predominantly young Caucasian children aged 6 months to 12 years of age. ${ }^{6-8}$

Several environmental risk factors have been implicated in development of myopia including family history ${ }^{9}$ and near work, ${ }^{10}$ while breastfeeding has been identified as a possible protective factor. ${ }^{11}$ Studies using primate and chick models have also served to better elucidate the biological basis of ocular growth and refractive development. Some of the agents identified in this process include dopamine, retinoic acid and acetylcholine. ${ }^{12,13}$

Two studies to date have shown a possible inverse relationship between parental smoking - with resultant passive exposure to nicotine-and childhood myopia, ${ }^{14,15}$ but none have examined this relationship in very young children. The association between parental smoking and childhood refractive error 
warrants close attention due to the purported role of nicotinic receptors in ocular development. This paper aims to examine the association between parental smoking and myopia as determined by a populationbased survey of very young Singapore Chinese preschool children aged between 6 and 72 months.

\section{Methods}

\section{Study population}

The STrabismus, Amblyopia, and Refractive errors in Singaporean children (STARS) study is a populationbased study of Chinese children aged 6-72 months residing in government apartments in the South-western and Western regions of Singapore. A total of 5648 Chinese children using disproportionate stratified (by age group) random sampling were recruited. A household that had no eligible child (aged 6-72 months), had moved away from the residing address, or was nonChinese was considered 'ineligible' for recruitment. Children with chronic medical conditions were also excluded from the study. Out of 4164 eligible candidates, the response rate was $72.3 \%(n=3009)$.

\section{Ocular assessment}

Trained ophthalmic professionals comprising one ophthalmologist, two optometrists, and one orthoptist performed eye examinations for all the children. For refractive assessment, cycloplegia was induced with one drop of $2.5 \%$ phenylephrine and three drops of $1 \%$ cyclopentolate $(0.5 \%$ for children less than 12 months of age) given at 5 -min intervals.

Children aged 24-72 months underwent autorefraction using a table-mounted autorefractor Canon RK-F1 (Canon Inc., Tokyo, Japan) while those aged 12-23.9 months underwent autorefraction with a hand-held Retinomax K-PLUS 2 (Right Medical Inc., Virginia Beach, VA, USA). The average of five readings was recorded for each child and the auto-refractors were calibrated daily before use. Children aged 6-11.9 months and those who failed autorefraction underwent streak retinoscopy (Welch Allyn, Chessy, France).

\section{Questionnaire}

The children's parents underwent an intervieweradministered general questionnaire to obtain information on parental smoking history and other demographic data.

History of whether either of the parents were current smokers, ex-smokers, and whether either of them smoked during pregnancy was obtained. The average number of cigarettes smoked by both parents and the point of time during pregnancy in which mother may have smoked were assessed.
Questions on family history, pregnancy, general health, past ocular history of the child, and on outdoor, indoor, and preschool activities of the child were also asked during the interview.

Before any testing, a participant information sheet was given and explained by an optometrist and a written consent was obtained from all children's parents. Approval was obtained from the Ethics Committees of the Singapore Eye Research Institute and the National Healthcare Group.

\section{Definitions}

Spherical equivalent refraction (SER) was defined as 'sphere plus half cylinder'. The definition of myopia was SER of at least -0.5 dioptres (D). The correlation (Spearman correlation coefficient) between the SER of the left eye and right eye within this study was $0.95(P<0.05)$ and thus only right eye data were analysed.

\section{Statistical analysis}

Statistical analysis was conducted using SPSS version 17 (SPSS Inc., Chicago, IL, USA). The association between the prevalence of myopia and parental smoking or other socio-demographic variables was determined using $\chi^{2}$ test for categorical variables and $t$-test for quantitative data. For the SER of the right eye, Pearson's correlation coefficients were computed for quantitative variables. ANOVA F-test was used in replacement of $t$-test for any categorical variables with more than two groups.

Subsequently, we modelled myopia outcome using a multiple logistic regression model, with adjustment of gender, age, total family income, parental education level, child's height, reading, time spent outdoors, and parental myopia status. In addition, we modelled the SER using a multiple linear regression model with adjustment of the same factors. Statistical significance was defined as $P$-value $<0.05$.

\section{Results}

\section{Study population}

A total of 3009 children aged 6-72 months (mean age $=40.5$ months) were examined, of whom 1570 (52.2\%) were boys and $1439(47.8 \%)$ were girls. There was no significant difference between participants $(n=3009)$ and nonparticipants $(n=1155)$ for age $(P=0.98)$ and gender $(P=0.67)$. However, a greater proportion of participants lived closer to the clinical examination sites $(P<0.001)$.

\section{Myopia prevalence}

SER was recorded in $2639(87.7 \%)$ of these children, of whom $52.1 \%$ were boys and $47.9 \%$ were girls. ${ }^{3}$ The mean SER for all children was 0.69D (SD: 1.15D). 
Overall adjusted prevalence of myopia (at least $-0.50 \mathrm{D}$ ) was $11.0 \%$ in children aged 6-72 months. When stratified by age, myopia prevalence was $15.1 \%$ in children aged 6-23.9 months and $10.3 \%$ in children aged 24-72 months $(P=0.001)$. When myopia was defined as SER of at least $-1.00 \mathrm{D}$, the overall prevalence of myopia was $5.2 \%$.

\section{Parental smoking}

Out of 2962 fathers questioned, 1100 fathers (37.1\%) had a history of having ever smoked (Figure 1). Of 2968 mothers questioned, 272 mothers (9.2\%) had a history of having ever smoked. Overall, 948 fathers had smoked during the child's life, whereas 197 mothers had smoked during the child's life. Sixty-four of the mothers (1.9\%) had a history of having ever smoked during pregnancy, of whom $51 \%$ smoked during the first month of pregnancy only.

\section{Parental smoking and childhood myopia}

Multivariate analysis (adjusted for age, gender, total family income, father's education, mother's education, height, parental myopia, read words or picture books, and total time spent outdoors) revealed decreased odds ratio (OR) of 0.50 (95\% confidence interval (CI): 0.30 $0.84), P=0.01$ ) of childhood myopia in children with a positive maternal history of ever smoking (Figure 2, Table 1). Decreased OR of 0.39 (CI: $0.20-0.76, P=0.01$ ) was also found in children with positive maternal history of smoking during the child's life whereas maternal smoking during pregnancy showed no significant relationship (OR 0.39, 95\% CI: 0.12-1.34, $P=0.14$ ).

Paternal history of smoking was also associated with decreased OR of childhood myopia (OR 0.72 (CI: 0.54-0.96), $P=0.02$ ).

\section{Discussion}

This is the first large-scale study undertaken in children of a very young age group-6-72 months of age- - to reveal such an inverse association between parental

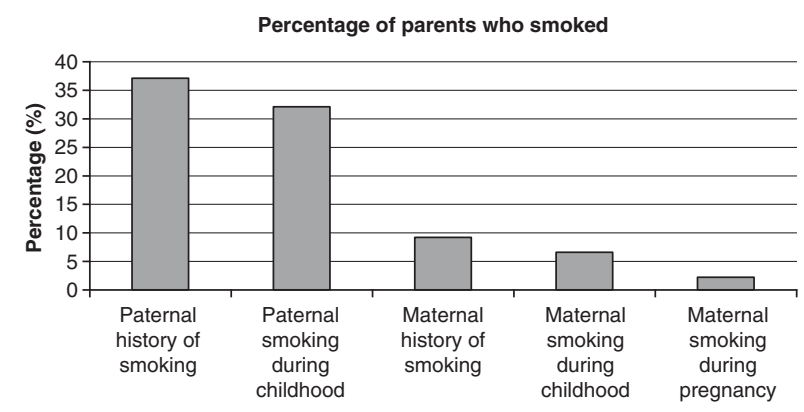

Figure 1 Percentage of parents who smoked cigarettes.

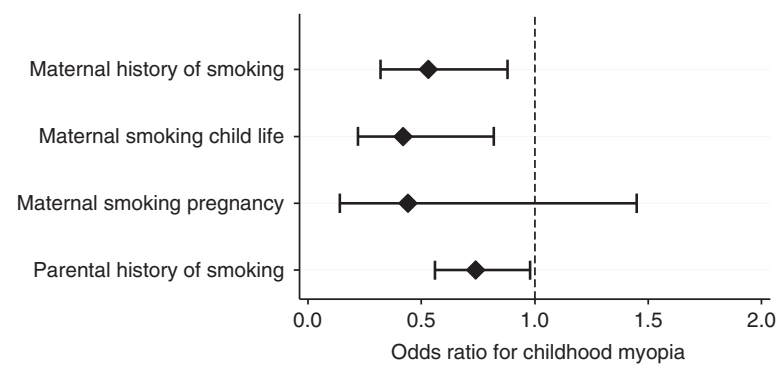

Figure 2 Parental smoking and childhood myopia.

Table 1 Association of smoking by each parent with Myopia in children

\begin{tabular}{|c|c|c|c|c|}
\hline \multirow[t]{2}{*}{ Parental smoking } & \multicolumn{2}{|c|}{$\begin{array}{c}\text { Mother } \\
\text { Multivariate }^{\mathrm{a}}\end{array}$} & \multicolumn{2}{|l|}{$\begin{array}{c}\text { Father } \\
\text { Multivariate }^{\mathrm{a}}\end{array}$} \\
\hline & OR $(95 \% \mathrm{CI})$ & $\mathrm{P}$ & OR $(95 \% C I)$ & $\mathrm{P}$ \\
\hline \multicolumn{5}{|l|}{ Smoking status } \\
\hline Never & 1 & & 1 & \\
\hline Current & $0.43(0.22-0.87)$ & 0.02 & $0.75(0.55-1.02)$ & 0.07 \\
\hline Past & $0.61(0.29-1.29)$ & 0.20 & $0.62(0.36-1.05)$ & 0.07 \\
\hline$P$ (trend) & & 0.03 & & 0.06 \\
\hline \multicolumn{5}{|l|}{ Ever smoked } \\
\hline No & 1 & & 1 & \\
\hline Yes & $0.50(0.30-0.84)$ & 0.01 & $0.72(0.54-0.96)$ & 0.02 \\
\hline \multicolumn{5}{|c|}{ Cigarettes smoked per day } \\
\hline$<6$ & 1 & & 1 & \\
\hline $7-12$ & $0.58(0.16-2.14)$ & 0.41 & $1.01(0.56-1.83)$ & 0.97 \\
\hline$>13$ & $1.24(0.23-6.69)$ & 0.80 & $1.24(0.67-2.28)$ & 0.50 \\
\hline$P$ (trend) & & 0.64 & & 0.72 \\
\hline \multicolumn{5}{|c|}{ Smoked during child's life } \\
\hline No & 1 & & 1 & \\
\hline Yes & $0.39(0.20-0.76)$ & 0.01 & $0.79(0.58-1.06)$ & 0.11 \\
\hline \multicolumn{5}{|c|}{ Number of years parent smoked during child's life } \\
\hline$<3.0$ & 1 & & 1 & \\
\hline$\geq 3.0$ & $0.79(0.04-16.3)$ & 0.88 & $1.16(0.48-2.80)$ & 0.75 \\
\hline \multicolumn{5}{|c|}{ Mother smoked during pregnancy } \\
\hline No & 1 & & NA & \\
\hline Yes & $0.39(0.12-1.34)$ & 0.14 & NA & \\
\hline
\end{tabular}

$P$-value based on linear trend test.

${ }^{\text {a }}$ Adjusted for age, gender, parenal income, father's education, mother's education, height, parental myopia, read words or picture books, and total time spent outdoor.

smoking and development of childhood myopia. Paternal and maternal history of smoking, were both associated with decreased OR of childhood myopia. This association between parental smoking and childhood refractive error warrants close attention due to the purported role of nicotinic receptors in ocular development. 
Prevalence of childhood myopia of at least $-1.00 \mathrm{D}$ was noted to be $5.2 \%$. This was similar to that found in a recent Taiwanese study that revealed a myopia prevalence rate of $5.8 \%$ in 7 -year-olds. ${ }^{16}$ It was higher, however, compared with that reported in Australian school students-less than $2 \%$ in children with mean age of 6.7 years. ${ }^{6}$

The main finding from our analysis, of the inverse association between parental smoking and early childhood myopia, is interesting.

A similar population study undertaken in 1999 and 2001 examining myopia and parental smoking in slightly older Singapore Chinese children revealed no significant trends between parental smoking and refractive error. ${ }^{14}$ It, however, revealed that children of mothers who ever smoked were more likely on average to have a hyperopic refractive reading than in children whose mothers did not smoke. The number of such mothers in the study population was, however, too low $(n=23)$ to make any further definitive conclusions.

Another recent population-based study ${ }^{15}$ in the United States examined the link between childhood myopia and exposure to parental smoking. This study found parental smoking (either by mother or father) to be associated with lower myopic prevalence and more hyperopic mean refractions. Smoking at home, smoking during the child's life, and smoking during pregnancy by either parent was inversely related to the development of childhood myopia. The mean age in this study population was 8.7 years (SD: 4.4 years) (range: $1-20$ years). The population was predominantly White $(53.6 \%)$ with the significant minority being Black (25.4\%). A total of $19.5 \%$ of the 342 children examined were found to have a myopic refraction with the myopic refraction being found in children of an older age group.

Several studies undertaken in chicks and primates have examined the biological basis of myopia. ${ }^{12,13}$ These studies have shown that visual input may modulate ocular growth and refractive development. Some of the identified biological agents involved in the process include dopamine, glucagon, retinoic acid, and acetylcholine. In addition, pharmacologic studies have revealed muscarinic receptors to have a role in refractive development-the antimyopic role of antimuscarinic agents such as atropine has already been noted ${ }^{17,18}$ _and atropine is being used in clinical practice in halting progression of myopia. However, the exact site and mechanism of action of atropine has yet to be clearly elucidated.

The purported role of nicotinic receptors has also yet to be discerned. There is minimal published data regarding the association between smoking or nicotinic receptor pharmacology and ocular development. To date, literature search revealed only one study that was undertaken in chicks, which found nicotinic antagonists to inhibit experimental myopia. ${ }^{19}$ Nicotine is an active constituent of cigarette smoke. As nicotinic acetylcholine receptors have a complicated pharmacology, nicotine can elicit a wide range of complex and sometimes conflicting biological effects in vivo based on temporal exposure patterns, genetics, specific neural pathways, and other parameters. ${ }^{15}$ Frequently, nicotine exposure induces a paradoxical upregulation of nicotinic receptors along with rapid receptor desensitization, sometimes causing agonists to behave as time-averaged antagonists in many biological systems. ${ }^{15}$ This might explain the result of reduced myopia rates found in children with exposure to parental smoking.

Although this was the first large-scale study to specifically assess refractive error and its possible relation to smoking in children of such a young age group, there are several limitations in the study that must be taken into account. First, cigarette smoke has many components besides nicotine, the passive exposure to which may confound the effects of nicotine per se on ocular and refractive development in young children. Second, this study was only undertaken in Chinese children and hence may not necessarily be extrapolated to ocular or refractive development in other races. Third, while less than a fifth of the children underwent refractive error assessment using the hand-held Retinomax-Retinomax has been known to give slightly more negative refractive readings - this might have confounded refractive error measurements used for analysis. Overall however, this study adds to the increasing body of evidence that nicotinic receptors may be involved in ocular growth and refractive development.

In light of this finding of such an inverse association between smoking and development of myopia, further studies are suggested to better understand the role of nicotinic acetylcholine receptor pharmacology in ocular development and myopia. This may pave the way for the development of targeted treatment strategies for prevention of myopia.

\section{Summary}

What was known before

- There is a possible link between parental smoking and childhood refractive error.

- Nicotinic receptors may have a role in ocular development and refractive error.

What this study adds

- This is the first large-scale study revealing an inverse relationship between parental (both maternal and paternal) smoking and incidence of myopia in very young children.

- Data on parental smoking prevalence were also obtained for the Singapore Chinese populace. 


\section{Conflict of interest}

The authors declare no conflict of interest.

\section{Acknowledgements}

Research Grant from Ministry of Health, Singapore: NMRC/1009/2005.

\section{References}

1 Pararajasegaram R. VISION 2020 — the right to sight: from strategies to action. Am J Ophthalmol 1999; 128(3): 357-358.

2 Kempen JH, Mitchell P, Lee KE, Tielsch JM, Broman AT, Taylor HR et al. The prevalence of refractive errors among adults in the United States, Western Europe, and Australia. Arch Ophthalmol 2004; 122(4): 495-505.

3 Dirani M, Chan YH, Gazzad G, Hornbeak D, Leo SW, Selvaraj P et al. Prevalence of refractive error in Singapore Chinese children-the strabismus, amblyopia and refractive error in young Singaporean children (STARS) study. Invest Ophthalmol Vis Sci 2010; 51(3): 1348-1355.

4 He M, Zeng J, Liu Y, Xu J, Pokharel GP, Ellwein LB. Refractive error and visual impairment in urban children in southern china. Invest Ophthalmol Vis Sci 2004; 45(3): 793-799.

5 Lai YH, Hsu HT, Wang HZ, Chang SJ, Wu WC. The visual status of children ages 3 to 6 years in the vision screening program in Taiwan. J AAPOS 2009; 13(1): 58-62.

6 Ojaimi E, Rose KA, Morgan IG, Smith W, Martin FJ, Kifley A et al. Distribution of ocular biometric parameters and refraction in a population-based study of Australian children. Invest Ophthalmol Vis Sci 2005; 46(8): 2748-2754.

7 Giordano L, Friedman DS, Repka MX, Katz J, Ibironke J, Hawes $P$ et al. Prevalence of refractive error among preschool children in an urban population: the Baltimore Pediatric Eye Disease Study. Ophthalmology 2009; 116(4): 739-746.
8 Ip JM, Huynh SC, Robaei D, Kifley A, Rose KA, Morgan IG et al. Ethnic differences in refraction and ocular biometry in a population-based sample of 11-15-year-old Australian children. Eye 2008; 22(5): 649-656.

$9 \mathrm{Wu}$ MM, Edwards MH. The effect of having myopic parents: an analysis of myopia in 3 generations. Optom Vis Sci 1999; 76(6): 387-392.

10 Ip JM, Saw SM, Rose KA, Morgan IG, Kifley A, Wang JJ et al. Role of near work in myopia: findings in a sample of Australian school children. Invest Ophthalmol Vis Sci 2008; 49(7): 2903-2910.

11 Chong YS, Liang Y, Tan D, Gazzard G, Stone RA, Saw SM. Association between breastfeeding and likelihood of myopia in children. JAMA 2005; 293(24): 3001-3002.

12 Morgan IG. The biological basis of myopic refractive error. Clin Exp Optom 2003; 86(5): 276-288.

13 Beuerman RW, Saw SM, Tan DTH, Wong TY. The relevance of studies in chicks for understanding myopia in humans. In: MYOPIA. Animal Models to Clinical Trials. World Scientific Publishing Co.: Singapore, 2010, pp 239-266.

14 Saw SM, Chia KS, Lindstrom JM, Tan DTH, Stone RA. Childhood myopia and parental smoking. Br J Ophthalmol 2004; 88: 934-937.

15 Stone RA, Wilson LB, Ying G, Liu C, Criss JS, Orlow J et al. Associations between childhood refraction and parental smoking. Invest Ophthalmol Vis Sci 2006; 47: 4277-4287.

16 Lin LL, Shih YF, Hsiao CK, Chen CJ. Prevalence of myopia in Taiwanese schoolchildren:1983-2000. Ann Acad Med Singapore 2004; 33(1): 27-33.

17 Kennedy RH. Progression of myopia. Trans Am Ophthalmol Soc 1995; 93: 755-800.

18 Raviola E, Wiesel TN. An animal model of myopia. N Eng J Med 1985; 312: 1609-1615.

19 Stone RA, Sugimoto R, Gill AS, Liu J, Capenhart C, Lindstorm JM. Effects of nicotinic antagonists on ocular growth and experimental myopia. Invest Ophthalmol Vis Sci 2001; 42: 557-565. 